Goldschmidt 2021 Abstract

https://doi.org/10.7185/gold2021.7075

\section{Critical Metal Distribution and Partitioning between Co-Existing Sulfides of the Massive Sulfide Deposits of the Bathurst Mining Camp, New Brunswick, Canada}

\section{AZAM SOLTANI DEHNAVI}

Yachay Tech University, Imbabura

Presenting Author: azam.soltani@utoronto.ca

The Bathurst Mining Camp is historically famous for producing $\mathrm{Zn}, \mathrm{Pb}, \mathrm{Cu}$, and by-products of $\mathrm{Au}$ and $\mathrm{Ag}$. This study used LA-ICP-MS to examine a range of critical metals such as $\mathrm{As}, \mathrm{Bi}, \mathrm{Co}, \mathrm{Cd}, \mathrm{Hg}$, In, Ga, Ge, Sb, Se, Sn, Te, and Tl within the various sulfide assemblages of ten deposits. The results show systematic mineral-specific elemental partitioning which can be related to element oxidation state, ionic radii of the substituting elements, element availability in each system, and the capacity of each sulfide structure to host trace elements. The critical metal inventories of the banded sulfide and basal sulfide facies are distinctive. The banded sulfide facies is dominantly comprised of sphalerite, galena, and pyrite, in which sphalerite is enriched in Cd (highest in Canoe Landing Lake and Louvicourt deposits), followed by In (highest in Brunswick No. 12 deposit) and $\mathrm{Hg}$ (highest in Louvicourt and Canoe Landing Lake deposits). Gallium and Germanium occur in minor concentrations within sphalerite of the BMC. Galena is the key host for Ag, Tl, Bi, and $\mathrm{Sb}$ in this assemblage and confirms the coupled substitution $\mathrm{Ag}^{+}+(\mathrm{Bi}, \mathrm{Sb})^{3+} \leftrightarrow 2 \mathrm{~Pb}^{2+}$, in which $\mathrm{Tl}^{+}$is documented to be principally hosted within galena as well.

Within the basal sulfide facies, chalcopyrite, pyrrhotite, and pyrite are the major phases. Chalcopyrite is notably enriched in $\mathrm{Sn}$, In, and Ag, however, if minor sphalerite co-exists with chalcopyrite, In is principally partitioned in sphalerite. Pyrrhotite hosts Se followed by As and $\mathrm{Bi}$. It is important to note that where the minor occurrence of arsenopyrite and tetrahedrite-tennantite happens, the expected partitioning of elements in the aforementioned sulfide assemblages gets disturbed. For example, tetrahedrite-tennantite accommodate a much higher concentration of $\mathrm{Sb}, \mathrm{Ag}$, and As. Also, most pyrite types of the $\mathrm{BMC}$ are arsenian pyrite and enriched in Co.

Distinctive correlation between elemental partitioning within various facies shows the physicochemical condition of the formation of massive sulfide deposits. Also, a specific signature of the critical metals is distinguished for individual deposits, which is linked to subtle genetic models and magmatic metal source contribution. Finally, the effect of metamorphism on the re-distribution of critical metals is addressed.
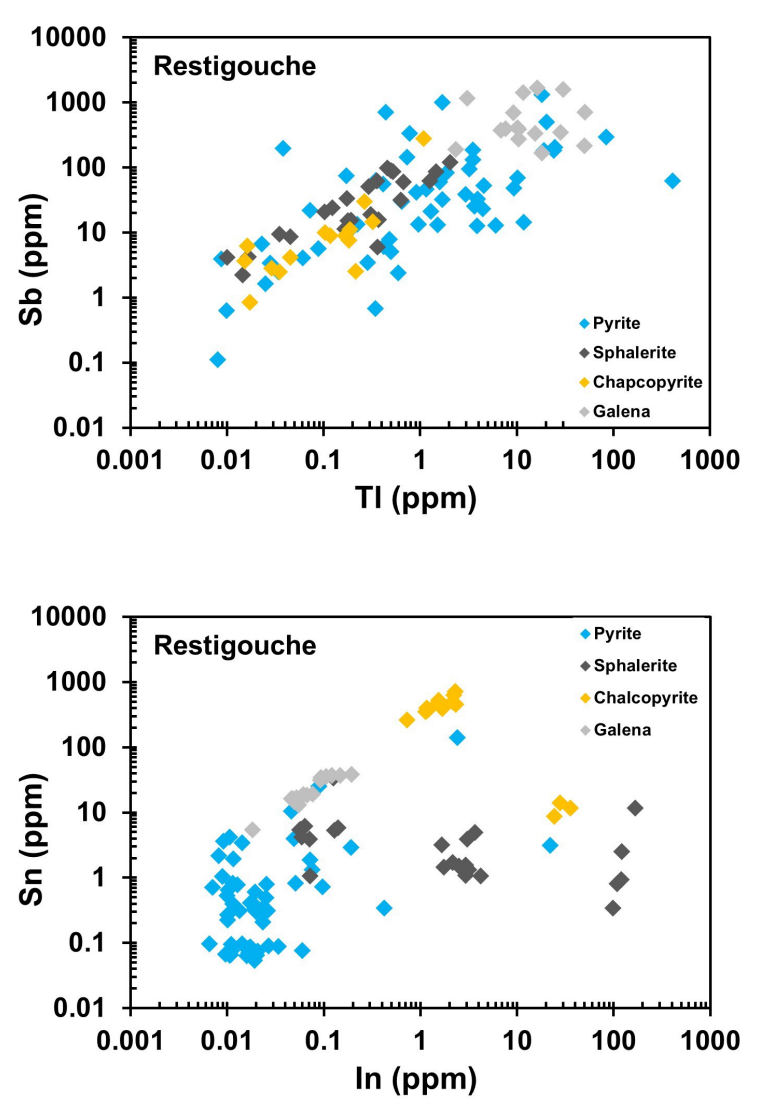